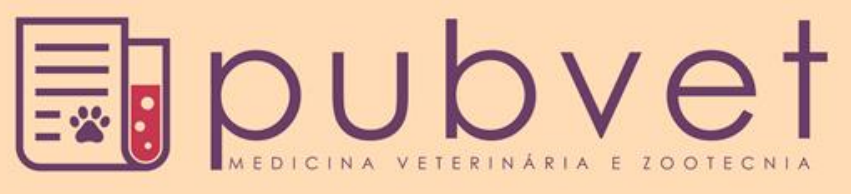

ISSN $1982-1263$

https://doi.org/10.31533/pubvet.v12n8a141.1-8

\title{
Relação homem versus touro nas arenas de rodeio
}

\author{
Matheus Hernandes Leira ${ }^{1^{*}}$, Gabriel Cristino Colsani ${ }^{2} \bullet$, Hortência Aparecida \\ Botelho $^{3}$, Bianca Batista Barreto ${ }^{\circ}$, Hadassa Cristhina de Azevedo Soares dos \\ $\operatorname{Santos}^{4}{ }^{\bullet}$, Lucas Silva Reghim ${ }^{5} \bullet$
}

${ }^{I}$ Professor e Pesquisador, Doutor pela Universidade Federal de Lavras - UFLA, Brasil.

${ }^{2}$ Discente do Curso de Medicina Veterinária - Centro Universitário Barão de Mauá - CUBM - Ribeirão Preto, Brasil.

${ }^{3}$ Mestre e Doutoranda pela Universidade Federal de Goiás - UFG, Brasil.

${ }^{4}$ Professa e Pesquisadora do Centro Universitário do Sul de Minas - UNIS, Brasil.

${ }^{5}$ Discente do Curso de Medicina Veterinária - Centro Universitário do Sul de Minas - UNIS, Brasil.

*Autor para correspondência, E-mail: matheushernandes@uol.com.br

RESUMO. O Rodeio foi reconhecido como um esporte competitivo durante as primeiras décadas do vigésimo século, o objetivo deste trabalho é mostrar a relação do peão que é um atleta e sua relação com os touros de rodeio, o peão deve permanecer sobre o animal durante oito segundos segurando-se apenas com uma mão em uma corda (montarias em touros) ou sela (montarias em cavalos) de acordo com a modalidade de montaria, a outra mão deve ser colocada para cima e caso encoste-a no animal ou na cerca o atleta é desclassificado, logo após a montaria o touro para de pular. Este esporte é conhecido pela força muscular, agilidade, equilíbrio e coragem com que os competidores enfrentam os animais treinados, entretanto, grande parte dos estudos relacionados ao rodeio competitivo prioriza os aspectos psicológicos e as lesões ocorridas nesse esporte, não caracterizando o perfil de aptidão física de seus participantes, a grande diferença de força e peso entre os atletas e os animais.

Palavras chaves: Bem-estar animal, arena de rodeio, montaria em touros

\section{Relation between man and bull in the rodeo arenas}

ABSTRACT. The Rodeo was recognized as a competitive sport during the first decades of the twentieth century, the aim of this work is to show the relationship of the pedestrian who is an athlete and his relationship with the rodeo bulls. The pawn should remain on the animal for eight seconds by holding only one hand on a rope (bull riding) or saddle (riding on horses) according to the riding mode. The other hand must be placed upwards and if it is touched on the animal or on the fence the athlete is disqualified, soon after riding the bull stops jumping. However, most of the studies related to competitive rodeo prioritize the psychological aspects and the injuries that occurred in this sport, not characterizing the profile of physical fitness. This sport is known for the muscular strength, agility, balance and courage with which competitors face trained animals. of its participants, the great difference of strength and weight between athletes and animals.

Keywords: Animal welfare, rodeo sand, bull riding

\section{Relación hombre versus toro en las arenas de rodeo}

RESUMEN. El Rodeo fue reconocido como un deporte competitivo durante las primeras décadas del vigésimo siglo, el objetivo de este trabajo es mostrar la relación del peón que es un atleta y su relación con los toros de rodeo. El peón debe permanecer sobre el animal durante ocho segundos sosteniéndose sólo con una mano en una cuerda (monturas en toros) 
o sella (monturas en caballos) de acuerdo con la modalidad de montaje. La otra mano debe ser colocada hacia arriba y si la apoya en el animal o en la cerca el atleta es descalificado, poco después de montar el toro para saltar. Este deporte es conocido por la fuerza muscular, agilidad, equilibrio y coraje con que los competidores enfrentan a los animales entrenados, sin embargo, gran parte de los estudios relacionados al rodeo competitivo prioriza los aspectos psicológicos y las lesiones ocurridas en ese deporte, no caracterizando el perfil de aptitud física de sus participantes, la gran diferencia de fuerza y peso entre los atletas y los animales.

Palabras claves: Bienestar animal, arena de rodeo, cabalgar en toros

\section{Introdução}

No começo a relação animal versus humano era apenas por necessidade, os cães vigiavam aldeias, ajudavam a caçar e pastorear; gatos eram bem-vindos por exterminar ratos e outras pragas; os pássaros alegravam as casas; os bovinos serviam como meio de locomoção e os demais animais eram para consumo alimentar ou contribuíam para a produção de outros alimentos, entretanto, essa interação pode ter começado em razão do frio e fome.

Para se livrar do frio, o homem das cavernas dormia com o cão e, como retribuição, dava-lhe restos de comida, com isso, livrava-se também do lixo, assim, com o tempo, cães, gatos e aves passaram a se aproximar dos homens, que tinham comida em abundância e a ofereciam aos animais, desencadeando na domesticação destes que deixavam de ser selvagens, essa aproximação proporcionou conforto e segurança aos animais.

Porém, acarretou na perda de espaço para atividades físicas e comprometimento da convivência em grupo, o que, segundo especialistas, tornam os animais cada vez mais diferentes de seus ancestrais selvagens, mas com o tempo alguns bichos começaram a ser domesticados, e hoje, alguns deles, por incrível que pareça, já são até considerados membros da família, comprovadamente, os animais humanos e não-humanos possuem características em comum, ainda que desenvolvidas em diferentes graus e de acordo com cada espécie, mas todos são portadores de instintos e de certas finalidades como a sobrevivência e a procriação; possuem noção de autoridade, bem como interação e comunicação.

Interação homem versus animal é o aspecto chave da produção animal moderna, sendo variáveis a intensidade e o tempo que desprendemos interagindo, por exemplo, com os bovinos, de acordo com o sistema de produção adotado. Pesquisas têm demonstrado que a qualidade da relação desenvolvida entre humanos e animais pode ter efeitos surpreendentes em ambos, humanos e bovinos de leite interagem diariamente, durante as atividades de rotina, podendo resultar em efeitos positivos ou negativos na produtividade e bem-estar animal.

Existem relatos de intensa interação entre humanos e bovinos de leite, pois, em qualquer sistema de criação para produção de leite, ordenhadores e vacas interagem diariamente por um longo período, durante o desenvolvimento das atividades de rotina: ordenha, alimentação, cuidados sanitários e outras práticas zootécnicas, entretanto, muitos estudiosos não reconheceram o relacionamento entre humanos e bovinos como valioso para ambas as partes, pois apontavam os bovinos puramente como objetos de trabalho, máquinas de produção, que não se alteram com os comportamentos humanos, ressalta-se, contudo, que a relação homem-animal não deve substituir a relação homem-homem, o cão não pode substituir um filho ou marido.

\section{Relação homem versus animal}

A criação de animais de estimação ou de companhia é uma característica universal nas sociedades humanas. $\mathrm{O}$ relacionamento entre homens e animais é uma entidade complexa iniciada nos primórdios da história da humanidade com a domesticação dos animais e mantida até hoje graças a sentimentos muito peculiares (Faraco \& Seminotti, 2004).

Desde que se iniciou a domesticação de nossos animais, a relação entre o tratador e os animais tem sido muito próxima, durante séculos, esta relação é simbiótica. Por exemplo, os bovinos dependem do homem para fornecer abrigo, nutrição e cuidados gerais, enquanto que o homem se beneficia do leite, carne, do esterco para combustível ou adubo, produção de calor, força de tração e mais recentemente na prática do esporte "rodeio" (English et al., 1992).

A maioria das propriedades eram pequena, e famílias inteiras viviam com um ou dois animais, 
a família e o gado frequentemente dividiam partes adjacentes da mesma habitação, especialmente depois da $2^{\text {a }}$ Guerra Mundial, as práticas mudaram, e o principal objetivo da maioria dos países tornar-se autossuficiente na agricultura e na produção animal, isto levou a um aumento no tamanho das propriedades, o que, no caso da produção animal, diminuiu a oportunidade de contato entre os tratadores e seus animais, além disso, foram introduzidas tecnologias que poupam mão-de-obra (comedouros automáticos, ordenhadeiras mecânicas) com uma redução substancial no tempo de contato (positivo) entre as pessoas e os animais.

Por outro lado, as tarefas aversivas associadas com o manejo animal permaneceram, como o transporte, medicação, vacinação, como consequência, os contatos remanescentes podem levar apenas a experiências negativas para os animais, causando reações de medo em relação ao homem, com possíveis consequências sobre o bem-estar e a produção animal.

O contato entre o tratador e os animais e suas consequências sobre o comportamento animal em uma propriedade, o tratador pode ter diferentes interações físicas e não-físicas com os animais, as interações físicas geralmente são feitas com as mãos e os braços, como tocar, acariciar, dar tapas, bater, ou incluir as mãos, como segurar uma vara para bater num animal, as interações não-físicas podem ser de diferentes tipos, como voz (intensidade, entonação), movimentos com o corpo, cheiro, ruído, pessoa se aproximando (Seabrook \& Bartle, 1992).

Geralmente, há uma mistura destas ações quando o tratador está trabalhando com os animais durante o arraçoamento, ordenha, supervisão, tratamentos médicos, movendo-os de um lugar para outro. Lensink et al. (2000a), em seu estudo sobre bezerros de leite comerciais alojados em gaiolas individuais, descreveram 15 contatos físicos e não-físicos diferentes do tratador com os bezerros durante o fornecimento de leite. A frequência dos contatos do tratador com os bezerros foi de 30 interações para os 100 bezerros, com uma amplitude de 0 a 75 por bezerro.

É a natureza e a frequência destes contatos que determinam, em grande parte, a reação do animal ao tratador e aos humanos em geral, vários projetos de pesquisa, a maioria conduzida com animais mantidos em condições intensivas (suínos, aves e bezerros de leite), demonstraram que os contatos físicos qualificados como "negativos" (bater, tapas) pelo observador induziram comportamento de retirada dos animais em relação ao tratador, o que geralmente foi interpretado como "medo".

Por exemplo, suínos que receberam um choque ou um tapa cada vez que se aproximaram de uma pessoa, tenderam a se aproximar com menor frequência ou mais lentamente desta pessoa que os animais que não receberam este tratamento (Gonyou et al., 1986; Hemsworth et al., 1986; Paterson \& Pearce, 1989). Resultados semelhantes foram verificados em bezerros de leite (Passillé et al., 1996; Lensink et al., 2000b).

Contatos físicos qualificados como "positivos" (tocar com cuidado, acariciar) reduzem a tendência de os animais evitarem o homem e aumentam sua tendência a interagir com ele (Gonyou et al., 1986; Tanida et al., 1995; Lensink et al., 2000b, c).

As interações não-físicas também são importantes para a reação dos animais ao homem, o fato dos animais verem o tratador durante o arraçoamento (que é algo recompensador para os animais) potencialmente faz com que os animais evitem menos o tratador e pode aumentar a tendência de interagirem com ele, alguns dos efeitos dos contatos "positivos" com os animais sobre o seu comportamento pode ser explicado pelo fato de serem frequentemente associados com o arraçoamento.

Jago et al. (1999) demonstraram que bezerros que receberam leite de uma pessoa que não interagia se aproximavam mais facilmente de uma pessoa desconhecida que os que receberam leite sem intervenção humana, este tratamento parece ser ainda mais eficiente do que contatos "positivos" (acariciar, deixar chupar os dedos) fora do horário de alimentação, além disso, em aves, a presença visual regular de um tratador reduziu as respostas de evitação das aves em relação ao homem (Jones, 1993; Barnett et al., 1994).

As respostas de medo depois de contatos "negativos" com o homem podem não só causar comportamento de evitação nos animais, como também respostas fisiológicas de estresse. Suínos que receberam contatos "negativos" (choque elétrico quando se aproximavam do homem) tiveram um maior aumento dos níveis sanguíneos de cortisol quando um homem entrava em sua baia do que suínos que tiveram contatos "positivos" como acariciar (Hemsworth et al., 1986). 
Da mesma forma, Boissy \& Bouissou (1988) demonstraram que novilhas acostumadas com contatos regulares não-aversivos com humanos (ser puxados por uma corda, acariciados) tiveram menor aumento dos níveis sanguíneos de cortisol e da frequência cardíaca depois de práticas comuns de manejo (captura, movimentar de um lugar para outro) do que novilhas que não receberam estes contatos não-aversivos. Vacas leiteiras maltratadas por uma pessoa (choque elétrico, batidas) também demonstram maior frequência cardíaca na ordenha quando esta pessoa está presente em comparação com outras vacas não-tratadas (Rushen et al., 1999). Estes resultados demonstram que um tratador (ou humanos em geral) pode estar na origem de respostas de estresse agudo, contatos regulares e a longo prazo também podem ter efeitos sobre as respostas de estresse crônico, o contato entre o homem e o animal também pode ter efeito sobre a qualidade da carne.

Em seu estudo de bezerros leiteiros, Lensink et al. (2001a) verificaram que bezerros originários de pessoas que tiveram um comportamento "positivo" com ele tiveram níveis de $\mathrm{pH}$ mais baixos e carne mais "clara' (apreciada pelos consumidores) do que os originários de pessoas que se comportavam mais "negativamente" a origem provável está nos efeitos do contato humano sobre o comportamento animal.

Bezerros originários de tratadores "positivos" eram mais fácil de carregar e descarregar no transporte e tiveram frequências cardíacas mais baixas durante o manuseio em comparação com os originários de tratadores "negativos', isto indica menor gasto de energia durante o manuseio e o transporte antes do abate, aumentando, portanto, o potencial glicolítico dos músculos importantes para a maturação da carne.

O contato com os animais pode auxiliar o homem em sua busca pelo conhecimento de si, no estabelecimento de sua identidade e na descoberta de suas próprias "realidades animais", eles podem representar a única ponte de ligação do homem com um mundo autêntico, sem hipocrisias, corporativismo ou mediocridade (Odendaal, 2000).

Alguns pesquisadores relataram à melhora psicológica e emocional do convívio homem e animal de estimação, revelando que a maioria dos proprietários de cães e gatos afirmou que a qualidade de vida melhorou após a introdução dos animais de estimação, sendo observado também, uma diminuição das tensões entre os membros da família aumentando a compaixão inclusive no convívio social (Barker \& Dawson, 1998).

Os animais têm características que ainda precisam ser amplamente estudadas, eles podem captar nossos sentimentos, expectativas e intenções, além de serem capazes de reconhecer nossa linguagem corporal e por meio dela captar nosso estado de espírito, também por meio das alterações químicas que ocorrem em nosso organismo podem identificar como está nosso humor, nossa saúde e nosso estado geral uma vez que possuem o olfato mais apurado que o nosso, além de captar frequências sonoras não detectáveis para o ser humano (Dukes, 1996).

$\mathrm{O}$ animal tem na vida do homem diversas funções, pode ser recurso alimentar e produtivo, companhia familiar, objeto de medo, pretexto de escárnio, elemento sacrificial, ser sagrado, presa de caça esportiva, ponto de comparação e símbolo social. Por vezes, dentro de uma mesma cultura ele pode ser amado, caçado, venerado, consumido, desprezado e objeto de tabu, seja em sua forma real ou simbólica, o animal está presente nos mitos, nas lendas, nas crenças e nas tradições acompanhando o homem em suas práticas culturais e de poder.

À mercê das complexidades socioculturais das humanidades, sua existência ou sua extinção está vinculada à relação que os homens estabelecem com a natureza. Nas sociedades ocidentalizadas, em que os seres humanos, em "estádio superior", buscam compreender e dominara a natureza pautados em perspectiva racionalizada desde o século XVIII - ocorreu distanciamento que deu lugar a uma infinita classificação e ordenação dos seres, a partir de lógica moderna e capitalista.

Em virtude desse distanciamento, que gerou maior incompreensão e desequilíbrio entre homem e natureza, surgiu, no discurso científico, a perspectiva de "harmonia universal", através dessa lógica, que não traduz a natureza real, fomos dela nos afastando cada vez mais sem perceber que a única maneira de o homem encontrar a harmonia com esse elemento do qual faz parte seria reintegrando-se a ele.

Nas sociedades africanas, cujas tradições orais apresentam concepção simbiótica do homem como um todo, centro de convergência de todas as coisas, vigora a ideia de que cada ser humano foi gerado a partir de uma parcela de tudo o que 
existiu antes dele, certamente a natureza tem conotação completamente diferente, e, portanto, a relação com os animais também.

A ciência já sabia que os homens e os bovinos divergiram de um ancestral comum que viveu há 95 milhões de anos, segundo Harris Lewin, da Universidade de Illinois em Urbana-Champaign, Estados Unidos, e um dos principais analistas do genoma bovino, apesar desse longo período de evolução, os bovinos e humanos ainda assim conservam um grande grau de similaridade entre suas arquiteturas, inclusive muito maior do que entre o homem e o camundongo, um modelo experimental amplamente empregado pela pesquisa biomédica.

O genoma bovino tem pelo menos 22 mil genes e a maioria dos cromossomos corresponde na sua totalidade, ou em partes, aos cromossomos humanos, essa é uma das principais conclusões do projeto "Sequenciamento do Genoma Bovino", publicado na revista norte-america Science, uma das importantes do mundo, editada pela Sociedade Americana para o avanço da ciência, os resultados práticos dessa pesquisa podem, por exemplo, beneficiar a produção de carne e leite na melhoria da qualidade dos produtos derivados do boi. O estudo foi realizado por um consórcio de 305 pesquisadores de 25 diferentes países, incluindo a USP Ribeirão, teve por objetivo sequenciar o genoma do boi e descrever como os genes estão ordenados no genoma, além de anotar as sequências, ou seja, adicionar a elas informação sobre a função biológica das proteínas que esses genes codificam para conhecer melhor a evolução dos bovinos e suas características biológicas.

\section{Treinamento do peão e touro nas arenas}

A prática esportiva envolvendo homem e animal é bastante antiga, os jogos e esportes envolvendo ambos é anterior ao nascimento de Cristo, onde na Grécia antiga, as corridas de carros ou "bigas" já faziam parte das provas de "jogos fúnebres", mandados celebrar por Tróia (Serra, 2000).

Esta prática esportiva era considerada na época o esporte dos homens poderosos que valorizavam e enalteciam seus animais; símbolos de poder e vaidade, acrescenta que "a exaltação aos animais era tão grande que, em alguns casos, cavalos famosos eram às vezes, enterrados ao lado de seus donos". Através do tempo, pôde-se observar o conjunto homem e animal em vários outros esportes (Serra, 2000), indica que existem duas formas de prática esportiva relacionando homem e animal; "a primeira na qual o homem faz conjunto com os animais e, a segunda, esportes contra os animais", em relação ao conjunto homem-animal (esportes com animais) encontramos algumas provas de rodeio, que também foram classificadas como "tradicionais".

O nome rodeio provém do espanhol, e são competições que se realizavam em caráter festivo, que consistiam na demonstração da habilidade em atividades ligadas a pecuária, e de acordo com regras especificadas, o cavaleiro tem de domar cavalos selvagens, cavalgar bois, laçar e imobilizar um novilho" ( $\underline{\text { Serra, 2000)}}$.

O rodeio é um esporte radical e de grande risco de lesões e até óbitos e que exige muito dos atletas em curto espaço de tempo, a escolha da modalidade montarias em touro (Bull Riding) se deu pelo fato de ser a modalidade mais radical do rodeio e a que mais riscos proporciona aos atletas devido ao peso dos animais que em média pesam uma tonelada ou mais e dos pulos destes animais serem maiores e mais diversificados, gerando mais dificuldades e lesões em relação, por exemplo, aos cavalo que são bem mais leves e causam menos problemas, além de exigir menos fisicamente dos competidores.

$\mathrm{O}$ rodeio exige muito dos atletas que $\mathrm{o}$ praticam, pois demanda claramente uma grande aptidão física e muita coragem, o que demanda grande preparação física e mental e para quem conhece uma festa de peão e feira agropecuária onde é realizada a maioria dos rodeios, sabe que fica muito difícil manter a concentração diante de tanto barulho de som altíssimo, fogos de artificio e as brincadeiras dos locutores.

Segundo (Leira et al., 2017), foram os norteamericanos que organizaram os rodeios como esporte com competições e regras, em 1980 chegou ao Brasil a modalidade montaria em touros, tendo a partir daí se tornado uma das maiores atrações das festas de rodeio, em 2001 essa modalidade passou a ser reconhecida como esporte regulamentado de acordo com a Lei $\mathrm{n}^{\mathbf{o}}$ 10.220, de 11 de abril de 2001. Posteriormente, em 2002, um novo projeto de lei (116/2001) exigiu que os organizadores de tais eventos disponibilizassem peões auxiliares, ambulâncias e médicos do mesmo modo que requer do atleta participante um seguro de vida

Este esporte é famoso pela agilidade, equilíbrio, força muscular e coragem com que os 
competidores encaram os animais treinados, durante a competição o atleta precisa manter-se por oito segundos sobre o animal, equilibrando-se com apenas uma mão em uma corda, enquanto a outra mão dever ser mantida para cima a fim de impedir o contato da mesma com o animal ou com a cerca evitando a desclassificação do atleta (Meyers et al., 2003).

A enorme diferença de peso e força entre os animais e os atletas submete o atleta, na maioria das vezes, a um extremo estresse físico que pode levar a inúmeras lesões, contudo, mesmo com toda a evolução nas últimas décadas, com presença de juízes especializados em análise de montarias, animais treinados e prêmios para os vencedores das provas, ainda é raro um programa de treinamento exclusivo para desenvolver as atividades específicas para o rodeio competitivo (Bergmaschi et al., 2006).

Leira et al. (2017) expõem que os itens obrigatórios de segurança para a prática do esporte são colete, calça de couro, espora e luva, e como equipamentos opcionais o capacete e o protetor bucal, a montaria em touro é tida como a prova mais radical do rodeio, além de ser a que mais exige preparo físico e mental do atleta, havendo um alto risco de acidentes com fraturas e contusões e correr até mesmo o risco de morrer, nessa modalidade não se usa sela e sim apenas uma corda americana que é onde o atleta com apenas uma das mãos se equilibra sobre o animal.

Meyers \& Laurent (2010a) manifestaram que competições de rodeio são muito conhecidas por meio da sua atmosfera de alto impacto, avaliado por muitos como um esporte ousado, com elevada exposição a lesões e traumas frequentes, as situações onde há o contato humano/ animal compreendem a $80 \%$ das lesões apresentadas com traumas em região torácica, abdominal, cadeia posterior de tronco e articulações como ombro e joelho, os traumas graves incluem rupturas ligamentares, fraturas, luxações, subluxações, pneumotórax, concussões e neuropraxias diversas.

Doimo \& Jimenez (2007) descreveram que os segmentos corporais mais acometidos em atletas de montaria em touro foram as coxas, joelhos e ombros, uma vez que a montaria em touro é considerada um esporte perigoso exigindo um elevado grau de habilidade do atleta, se faz importante observar e avaliar sob diferentes enfoques os dados referentes às lesões para se elaborar mecanismos de prevenção e uma eficaz minimização de riscos e sequelas decorrentes da prática desse esporte.

Para Meyers \& Laurent (2010b), os principais mecanismos de lesões são decorrentes da idade, imaturidade física, fadiga, experiência, comportamento, peculiaridade violenta do esporte e déficit de intervenção médica apropriada, quando há um plano de treino traçado especialmente para o esporte específico, o condicionamento maximiza o potencial atlético, minimizando a predisposição a lesões além de tornar mais rápida a recuperação.

Ainda de acordo com Meyers \& Laurent (2010b), fica claro que o uso do preparo físico com técnicas adequadas de treinamento minimiza significativamente o número de lesões sofridas, pois melhora a flexibilidade e resistência orgânica exigidas na ocasião de se manter em cima do touro, diminuindo a quantidade de acidentes mais graves, a partir do momento em que um peão sobe em um touro e parte para a arena, ele se torna o centro do mundo. Mundo este que a maior parte das pessoas não conhece, mas que envolve uma quantidade enorme de pessoas, sentimentos e preparativos.

\section{As regras das competições}

Dentro do brete, peão e touro se preparam para entrar na arena, aberto o portão, o homem tem que se manter por pelo menos oito segundos em cima do touro, uma das mãos deve estar agarrada a uma corda presa no touro, a chamada corda americana, a outra deve se manter erguida e caso esbarre na grade, ou no próprio bicho, o peão recebe nota zero, mas somente os oito segundos não são suficientes para um peão se tornar vencedor. A desenvoltura durante a montaria também conta, dois juízes avaliam a performance e dão notas separadas para o competidor e o animal, o resultado final é a soma de $50 \%$ da nota do peão e $50 \%$ da nota do touro, e pode variar de zero a 100 pontos, vence aquele que conseguir a maior média.

\section{Conclusão}

O rodeio é um esporte que cresceu e evoluiu muito rápido com o passar dos anos, além de ser muito popular em nosso país, os atletas dessa modalidade merecem a mesma atenção e estudo de seu preparo físico, como acontece em outros esportes que se beneficiam cada vez mais da ciência e tecnologia para melhoria constante de seu desempenho. O rodeio nesta expectativa pode 
ser observado como um dos símbolos das 'comunidades' que compõem a cultura regional ou nacional, pois está imbuído de elementos que o fazem ser considerado uma comunidade, tais como o forte sentimento de amizade e companheirismo que une os peões, tropeiros e os touros de rodeio.

\section{Agradecimentos}

Coordenação de Aperfeiçoamento de Pessoal de Nível Superior (CAPES), Concelho Nacional de Desenvolvimento Científico e Tecnológico (CNPq) e Universidade Federal de Lavras (UFLA).

\section{Referências bibliográficas}

Barker, S. B. \& Dawson, K. S. 1998. The Effects of Animal-Assisted Therapy on Anxiety Ratings of Hospitalized Psychiatric Patients. Psychiatric Services, 49(6), 797-801.

Barnett, J. L., Hemsworth, P. H., Hennessy, D. P., MccalluM, T. M. \& Newman, E. A. 1994. The effects of modifying the amount of human contact on the behavioural, physiological and production responses of laying hens. Applied Animal Behaviour Science, 41, 87-100.

Bergmaschi, J. P., Matsudo, S. M. \& Matsudo, V. K. R. 2006. Relação da força de membros superiores e nível de atividade física com a prevalência de lesão e o desempenho de participantes de rodeio competitivo. RBCM, 14(1), 53-58.

Boissy, A. \& Bouissou, M. F., 1988. Effects of early handling on heifers' subsequent reactivity to humans and to unfamiliar situations. Applied Animal Behaviour Science, $20,259-273$

Doimo, L. A.; Jimenez, M. V. O. 2007. Lesões referidas em atletas de montaria em touros/Related injuries in athletes of bull riding. Fisioterapia Brasil, 8 (4) 239-242,

Dukes, H. H. 1996. Fisiologia dos Animais Domésticos (11a. ed., 840 p.). Guanabara Koogan, Rio de Janeiro, BR.

English, P. R., Burgess, G., Segundo, R. \& Dunne, J. 1992. Stockmanship: improving the care of the pig and other livestock. Farming Press Books, Ipswich, UK.

Faraco, C. B. \& Seminotti, N. 2004. A Relação Homem-Animal e a Prática Veterinária. Revista CFMV, 10(32), 57-62.
Gonyou, H. W., Hemsworth, P. H. \& Barnett, J. L. 1986. Effects of frequent interactions with humans on growing pigs. Applied Animal Behaviour Science, 16, 269-278.

Hemsworth, P. H., Barnett, J. L. \& Hansen, H. 1986. The influence of handling by humans on the behaviour, reproduction and corticosteroids of male and female pigs. Applied Animal Behaviour Science, 15, 303-314.

Jago, J. G., Krohn, C. C. \& Matthews, L. R. 1999. The influence of feeding and handling on the development of the human-animal interactions in young cattle. Applied Animal Behaviour Science, 62, 137-151.

Jones, R. B. \& Hughes, B. O. 1981. Effects of regular handling on growth in male and female chicks of broiler and layer strains. British Poultry Science, 22, 461-465.

Jones, R. B. 1993. Reduction of the domestic chick's fear of humans by regular handling and related treatments. Animal Behavior, 46, 991998.

Leira, M. H., Reghim, L. S., Peregrino, L. C., Honda, C. N., Félix, J. I. C, Silva, F. \& Cunha, L. T. 2017. A origem do rodeio no Brasil sua prática como esporte radical e o bem-estar dos animais de montaria. PUBVET, 11, 207-312.

Lensink, B. J., Boissy, A. \& Veissier, I. 2000a. The relationship between farmer's attitude and behaviour towards calves, and productivity of veal units. Annales de Zootechnie, 43, 313-327.

Lensink, B. J., Boivin, X., Pradel, P., Le Neindre, P. \& Veissier, I. 2000b. Reducing veal calves' reactivity to people by providing additional human contact. Journal of Animal Science, 78, 1213-1218.

Lensink, B. J., Fernandez, X., Cozzi, G., Florand, L., and Veissier, I., 2001a. The influence of farmers' behaviour towards calves on animals' responses to transport and quality of veal meat. Journal of Animal Science, 79, 642-652.

Lensink, B. J., Fernandez, X., Boivin, X., Pradel, P., Le Neindre, P. \& Veissier, I. 2000c. The impact of gentle contacts on ease of handling, welfare, and growth of calves, and quality of veal meat. Journal of Animal Science, 78, 1219-1226.

Lensink, B. J., Fernandez, X., Cozzi, G., Florand, L. \& Veissier, I. 2001. The influence of farmers' behaviour towards calves on animals' responses to transport and quality of veal meat. Journal of Animal Science, 79, 642-652. 
Lensink, B. J., Veissier, I. \& Florand, L. 2001b. The farmer's influence on calves' behaviour, health and production of a veal unit. Animal Science, 72(1), 105-117.

Meyers, M. C. \& Laurent, C. M. Jr. 2010a. The rodeo athlete: sport science: part I. Sports Medicine, 40(5), 31-417.

Meyers, M. C. \& Laurent, C. M. Jr. 2010b. The rodeo athlete: injuries - part II. Sports Medicine, 10(40), 39-817.

Meyers, M. C., Sterling, J. C. \& Souryal, T. O. 2003. Radiographic findings of the upper extremity in collegiate rodeo athletes. Medicine \& Science in Sports \& Exercise, 35(4), 543-547.

Odendaal, J. S. 2000. Animal-Assisted Therapy Magic or Medicine. Journal of Psychosomatic Medicine, 49(4), 275-280.

Passillé, A. M., Rushen, J., Ladewig, J. \& Petherick, C. 1996. Dairy calves' discrimination of people based on previous handling. Journal of Animal Science, 74, 969974.

Paterson, A. M. \& Pearce, G. P. 1989. Boarinduced puberty in gilts handled pleasantly or unpleasantly during rearing. Applied Animal Behaviour Science, 22, 225-233.

Rushen, J., De Passillé, A. M. B. \& Munksgaard, L. 1999. Fear of people by cows and effects on milk yield, behavior and heart rate at milking. Journal of Dairy Science, 82, 720-727.

Seabrook, M. F. \& Bartle, N. C. 1992. Human factors. In: Phillips, C. \& Piggins, D. (Eds.). Farms Animals and the Environment (p. 111125). CAB International, Wallingford, United Kingdom.

Serra, R. 2000. Rodeio: uma paixão! Gryphus, Rio de Janeiro, BR.

Tanida, H., Miura, A., Tanaka, T. \& Yoshimoto, T. 1995. Behavioural response to humans in individually handled weanling pigs. Applied Animal Behaviour Science, 42, 249-259.

Recebido: 4 Jul. 2018.

Aprovado: 17 Jul. 2018

Publicado: 18 Jul. 2018

Licenciamento: Este artigo é publicado na modalidade Acesso Aberto sob a licença Creative Commons Atribuição 4.0 (CC-BY 4.0), a qual permite uso irrestrito, distribuição, reprodução em qualquer meio, desde que o autor e a fonte sejam devidamente creditados. 